\title{
Tassara, Carlo. Cooperación internacional para el desarrollo: gobierno, economía y sociedad. Evolución de las políticas y escenarios futuros. Bogotá: Ediciones Unisalle. 2016. $132 \mathrm{pp}$.
}

Las desigualdades entre el Norte y el Sur del mundo, entre ricos y pobres, entre "globalizadores" y "globalizados", la convicción de que esta división del mundo responde a una injusticia que necesita ser enmendada para construir una sociedad más equitativa en la que todos, países e individuos, tengan la oportunidad de desarrollarse y aprovechar sus capacidades para mejorar sus niveles de vida, representan las bases de la que hoy llamamos cooperación al desarrollo.

Con esta premisa, y analizando inicialmente cómo la relación — conceptual y operativa - entre cooperación internacional y desarrollo haya mudado y evolucionado a lo largo de los años hasta declinar hacia

\footnotetext{
* Graduado en Economía en la Universidad de Pavía y magíster en Cooperación al Desarrollo y Ayuda Humanitaria (NOHA-Network on Humanitarian Assistance) en las universidades La Sapienza (Roma) y Deusto (Bilbao). Actualmente es el responsable de la Oficina de Cooperación de la AICS-Agencia Italiana para la Cooperación al Desarrollo en la Embajada de Italia en Bogotá. Correo electrónico: lucadepaoli@hotmail.com
} 
la concepción actual, en el libro que nos disponemos a reseñar ${ }^{1}$ Carlo Tassara $^{2}$ ofrece un análisis panorámico, oportuno y riguroso, sobre los cambios en las políticas de cooperación al desarrollo de los últimos setenta años, conjugando reflexiones e investigación crítica con la representación de los contextos políticos y socioeconómicos y los paradigmas que han influenciado y caracterizado su implementación.

¿Qué significa cooperar, y para qué tipo de desarrollo? ¿Quiénes son los principales actores y cómo se ha trasformado el modus operandi de la cooperación? ¿Cuáles son los retos del futuro? Este es el núcleo alrededor del cual se despliega la reflexión del autor.

El recorrido analítico del trabajo revela las contradicciones entre la retórica y la práctica de la cooperación, desnudando las ambigüedades que han caracterizado la ayuda oficial al desarrollo (AOD) en diferentes períodos históricos y desvela, al mismo tiempo, el enorme potencial de las estrategias de desarrollo. El autor basa su estudio en los fracasos irrefutables y en los resultados concretos obtenidos por gobiernos, organizaciones no gubernamentales y organismos internacionales.

Como se mencionó, el libro se fundamenta sobre el estudio de la relación dicotómica entre el Norte y el Sur del planeta, donde la AOD a menudo ha representado una herramienta para promover los intereses de los países más industrializados y del capitalismo internacional. Después de tantos años de cooperación, los resultados logrados están muy lejos de los esperados. Esta situación se torna aún más crítica si la contextualizamos en el escenario económico actual, que viene desacelerando las poderosas economías del hemisferio norte que,

\footnotetext{
1 El primer capítulo del libro se puede descargar gratuitamente en la red: https:// www.academia.edu/30742176/Cooperaci\%C3\%B3n_internacional_para_el_desarrollo_ gobierno_econom\%C3\%ADa_y_sociedad._Evoluci\%C3\%B3n_de_las_pol\%C3\%ADticas_y_escenarios_futuros Más información se encuentra disponible en http://ebooks. lasalle.edu.co/searchresults?option $=$ catalog\&keyword $=$ tassara\&type $=$ quick

2 Es profesor de la Università degli Studi di Roma La Sapienza y dicta clase de doctorado y maestría en la Universidad Externado de Colombia, la Universidad de los Andes, la Pontificia Universidad Javeriana y otros ateneos colombianos. Ver https://uniroma1.academia. edu/CarloTassara
} 
hasta hace poco, eran las protagonistas absolutas de la cooperación internacional para el desarrollo.

Por medio de un análisis elegantemente estructurado y documentado, gracias también a una vastísima bibliografía, Tassara nos muestra cómo el modelo predominante entre los años cincuenta y principios de los ochenta, aunque sujeto a juicios negativos e intentos de revisiones, ha sido principalmente económico y se ha fundamentado esencialmente en los criterios del crecimiento y de la industrialización. Por lo tanto, "el paradigma dominante se basaba en la total confianza en el crecimiento económico como el único camino a través del cual los países pobres podían lograr el desarrollo" (Tassara, 2016, p. 35). En esos años, la cooperación se caracterizaba por una marcada verticalidad en las relaciones entre Norte y Sur y operaba a través de transferencias de fondos que tenían lugar principalmente entre los Estados que, en ese momento, eran los únicos actores legitimados por el sistema internacional. Los países donantes establecían qué hacer y cómo hacerlo, mientras que las relaciones entre ellos y los países beneficiarios eran de carácter jerárquico y paternalista.

En los años noventa, la conceptualización del desarrollo humano genera un cambio radical en los paradigmas de la cooperación. El nuevo modelo asigna a la lucha contra la pobreza un papel central en las políticas de cooperación. La pobreza ya no se concibe como un "hecho objetivo", sino como la consecuencia histórica de procesos materiales y culturales, de acontecimientos políticos y económicos en los cuales la exclusión, la marginación y la alienación social se transforman en obstáculos para lograr un desarrollo más humano y solidario. En este renovado fermento ideal, y a la luz de los nuevos paradigmas, el autor observa y destaca el papel de algunos grupos sociales organizados en la conquista gradual de avances democráticos y del "derecho a contar" de los países del Sur del mundo. Hoy en día, "los actores de la cooperación ya no son únicamente los Estados nacionales, sino también los gobiernos subestatales (municipios, provincias, departamentos, etc.), las organizaciones de la sociedad civil, las universidades, los centros de investigación y el sector privado" (Tassara, 2016, p. 23). En especial este último, en virtud de 
la reflexión sobre la teoría y la práctica de la responsabilidad social empresarial y la creciente dificultad de los gobiernos para financiar la AOD, asumió de forma gradual un papel más importante en la cooperación mediante el aumento de la oferta de recursos destinados a financiar el desarrollo.

Estos nuevos enfoques y actores promueven una visión holística del desarrollo y afirman su necesidad de formular propuestas con soluciones técnicas apropiadas para enfrentar y desentrañar algunos problemas generales. El conocimiento de los contextos locales se convierte así en un elemento esencial en cualquier acción que pueda tener un efecto mayor. Como consecuencia, "el diálogo sobre las políticas globales, el interés mutuo, el partenariado, la participación activa y la apropiación por parte de los actores locales se han consolidado como enfoques y criterios metodológicos cada vez más universales" (Tassara, 2016, p. 23).

En el siglo XXI, los escenarios generados por la pos Guerra Fría, la crisis económica, los cambios inducidos por el tiempo de la globalización y la interdependencia a escala mundial, el surgimiento de nuevas formas de participación social en los países industrializados y emergentes, han vuelto inadecuada la caja de herramientas que la cooperación había utilizado anteriormente. En este contexto, el análisis de Tassara nos ayuda a entender cómo la división entre el desarrollo y el subdesarrollo es ya anacrónica, está sepultada por la nueva configuración geopolítica del mundo que ha convertido a los países que antes se consideraban "pobres" en importantes centros de referencia de la posmodernidad.

El autor reconoce que estos cambios se han producido a un ritmo más rápido que en cualquier otro momento de la historia; en consecuencia, "las relaciones entre los países del Sur y entre estos y los países del Norte han adquirido características completamente nuevas" (Tassara, 2016, p. 96). Temas como el cambio climático, la seguridad alimentaria, la protección del medio ambiente y la gobernanza de la economía y de la financiación no se pueden confinar geográficamente, sino que representan desafíos globales para toda la comunidad internacional y 
van más allá de la concepción clásica de las relaciones entre el Norte y Sur del planeta.

Estas transformaciones históricas también han producido la progresiva afirmación de nuevas formas de cooperación en las que los países emergentes desempeñan un papel de liderazgo. En este contexto, el rechazo a la globalización cultural y a la adopción del modelo occidental como única fuente del conocimiento y verdad irrefutable ejerce una labor relevante, lo que implica el riesgo de la destrucción de las especificidades culturales de cada territorio, constituidas y conformadas por historia, cultura, tradiciones, conocimientos y recursos humanos y naturales.

Es el caso de la cooperación Sur-Sur, que tiene lugar entre países en desarrollo y promueve actividades conjuntas entre Estados y pueblos emergentes, estructurada sobre la necesidad de mejorar y compartir las experiencias y habilidades adquiridas a nivel local. Según Tassara, la cooperación Sur-Sur debería ser ulteriormente valorizada y representar un complemento que enriquece la tradicional cooperación entre el Norte y el Sur del planeta, puesto que los elementos propios de esta cooperación son el espejo de los nuevos equilibrios de un mundo multipolar y permiten el crecimiento de metodologías innovadoras para el desarrollo. Sin embargo, algunos investigadores idealizan la cooperación Sur-Sur y le atribuyen únicamente características positivas: es horizontal, está basada en el respeto mutuo, garantiza siempre un alto nivel de participación, fortalece el desarrollo de las capacidades locales y no está supeditada a condicionalidades originadas por los intereses geopolíticos y comerciales del donante (Tassara, 2026, p. 93). Mientras que nuestro autor no rehúye críticas al modelo: la autoreferencialidad produce tergiversaciones en la percepción de las nuevas formas de cooperación, los intereses geopolíticos persisten como condición fuertemente distorsiva de las ayudas (como en el caso de la cooperación china), por lo que "habría que demostrar con los hechos, más que con la narración, que estas potencialidades se están efectivamente traduciendo en un valor agregado para los países que reciben la cooperación" (Tassara, 2016, p. 94). En este contexto, también la cooperación triangular representa una innovación importante. 
El autor concluye con algunas reflexiones esclarecedoras sobre los desafíos por venir: ¿cuáles escenarios se vislumbran para el pos 2015? ¿Qué hipótesis subyacen a la Agenda 2030 para el Desarrollo Sostenible? La Declaración de Busan (2011) ha marcado un punto de inflexión significativo y prevé la transición del concepto de eficacia de la ayuda al de eficacia del desarrollo, mientras que la Agenda 2030 y sus Objetivos de Desarrollo Sostenible (ODS) abren una nueva era de cooperación al desarrollo. No obstante, para el buen éxito de su aplicación, hace falta una gran cantidad de recursos económicos y humanos, tanto públicos como privados. Todos los Estados deben contribuir al esfuerzo para encauzar el mundo hacia un camino orientado a la sostenibilidad, sin distinción entre países industrializados, emergentes y en desarrollo, aunque las problemáticas específicas que cada uno de ellos tiene que enfrentar pueden ser diferentes. Para la concretización de la nueva agenda se necesita, además, la participación activa de todos los componentes de la sociedad civil, desde las organizaciones no gubernamentales hasta las empresas, desde las universidades hasta las fundaciones filantrópicas. Para el autor, todo esto requiere de un nuevo diálogo sobre el papel de las políticas de cooperación orientadas fuertemente hacia el desarrollo de los países receptores, renunciando de una vez por todas a subordinarlas a los intereses políticos y económicos de los países donantes, ya sean ellos del Norte o del Sur del mundo.

Con base en estas consideraciones, el profesor Tassara plantea tres posibles escenarios para la implementación de la Agenda 2030 en los próximos años. Una visión minimalista, sostenida en especial por la Unión Europea, que considera los ODS una versión actualizada de los Objetivos de Desarrollo del Milenio, aprobados en 2000, y focaliza su aplicación en la lucha contra la pobreza y el hambre, concentrando sus intervenciones en África subsahariana y en Asia meridional y suroriental. Un punto de vista basado en la seguridad, más cercano a las posiciones de los Estados Unidos, que da prioridad a los Estados frágiles y supedita "la cooperación para el desarrollo a las exigencias de la lucha contra el terrorismo transnacional, la delincuencia internacional organizada y el control migratorio" (Tassara, 2016, p. 110). El tercer enfoque, impulsado por la Comunidad de Estados Latinoamericanos y Caribeños (CELAC) y otros países emergentes, abraza los principios establecidos por la Declaración 
de Busan y propende por la creación de una asociación mundial para el desarrollo global, fomentando una propuesta más holística y sistémica para solucionar los grandes problemas de la humanidad. La fuerza con la que los diferentes actores se posicionarán en la escena internacional en los próximos años influenciará inevitablemente la prevalencia de uno de estos escenarios o, hipótesis aún más probable, la identificación de un punto de equilibrio entre ellos.

Hubiera sido interesante que el autor hubiese profundizado más en el estudio de los efectos, positivos y negativos, de la globalización en la economía internacional y en las políticas de desarrollo. Esto habría enriquecido todavía más el análisis de los posibles escenarios futuros de la cooperación. También hay que señalar que el momento en que se elaboró y se publicó la obra hizo imposible abordar adecuadamente los posibles efectos de la presidencia Trump sobre tales escenarios.

De todas maneras, el libro de Tassara se enmarca dentro de un debate abierto sobre el futuro de la cooperación internacional en los próximos años y consigue transmitir al lector la experiencia y el patrimonio de conocimiento crítico que el autor ha madurado al observar y al trabajar en este sector en los últimos treinta y cinco años. 